\title{
Pulmonary artery sealing with ultrasonic energy in open lobectomy: A phase I clinical trial
}

\author{
Eric Goudie, MD, Vicky Thiffault, BSN, Adeline Jouquan, MSc, Edwin Lafontaine, MD, \\ Pasquale Ferraro, MD, and Moishe Liberman, MD, PhD
}

\begin{abstract}
Objective: Pulmonary artery branch sealing in video-assisted thoracoscopic surgical lobectomy is usually achieved with vascular endostaplers. Iatrogenic pulmonary artery injury may be caused by endostaplers. We evaluated the safety of pulmonary artery sealing with an ultrasonic energy vessel-sealing device in a phase I clinical trial evaluating in vivo safety of the device during open lobectomy.

Methods: Patients scheduled to undergo elective open (thoracotomy) pulmonary lobectomy were prospectively enrolled. Target sample size was 10 patients. Pulmonary artery diameter was measured intraoperatively. All branches $\leq 7 \mathrm{~mm}$ were divided with an ultrasonic energy vessel-sealing device. The remainder of the lobectomy was performed in a standard fashion. Intraoperative and postoperative bleeding were strictly recorded.
\end{abstract}

Results: Eighteen patients were prospectively enrolled. Eight patients were not amenable to pulmonary artery sealing with the device. In the 10 patients included in the analysis, a total of 14 pulmonary arteries were sealed with the ultrasonic device. The mean vessel diameter was $5 \mathrm{~mm}$ (range, 2-7 $\mathrm{mm}$ ). One patient underwent reoperation for bronchial artery bleeding (vessel not sealed with device). There was no intra- or postoperative bleeding related to ultrasonic pulmonary artery sealing. There was no postoperative mortality.

Conclusions: Pulmonary artery sealing for vessels with diameter $\leq 7 \mathrm{~mm}$ was safely achieved with an ultrasonic energy vessel-sealing device in open lobectomy. The use of ultrasonic energy vessel-sealing devices in video-assisted thoracoscopic surgical lobectomy may have the advantage of making small, short, pulmonary artery branch sealing safer than with vascular endostaplers. Further studies are necessary before widespread application in lobectomy, including video-assisted thoracoscopic surgical lobectomy. (J Thorac Cardiovasc Surg 2017;153:1600-7)

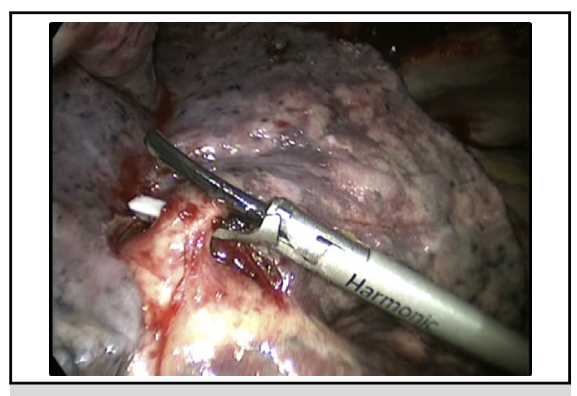

The ultrasonic energy device can safely seal pulmonary arteries with diameter $\leq 7 \mathrm{~mm}$.

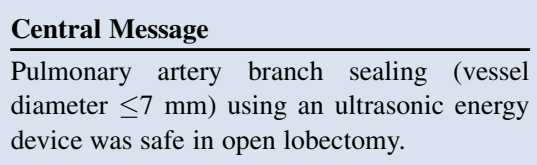

\section{Perspective}

Iatrogenic pulmonary artery (PA) branch injury may be caused by endostaplers, especially in short and small vessels during video-assisted thoracoscopic surgical lobectomy. Ultrasonic energy devices may make PA branch sealing safer due to a smaller footprint and userfriendly ergonomics. In this clinical trial, PA branch sealing with diameter $\leq 7 \mathrm{~mm}$ was safely achieved with an ultrasonic energy device in open lobectomy.

See Editorial Commentary page 1608.
From the Division of Thoracic Surgery, Department of Surgery, Centre Hospitalier de l'Université de Montréal Endoscopic Tracheobronchial and Oesophageal Center (CETOC), Endoscopic Tracheobronchial and Oesophageal Center, University of Montréal, Montréal, Québec, Canada.

This trial was funded by the Marcel and Rolande Gosselin Chair in Thoracic Surgical Oncology, University of Montreal, Montréal, Québec, Canada.

Read at the 96th Annual Meeting of The American Association for Thoracic Surgery, Baltimore, Maryland, May 14-18, 2016.

Received for publication May 25, 2016; revisions received Dec 9, 2016; accepted for publication Dec 30, 2016; available ahead of print March 20, 2017.

Address for reprints: Moishe Liberman, MD, PhD, Centre Hospitalier de l'Université de Montréal Endoscopic Tracheobronchial and Oesophageal Center (CETOC), Division of Thoracic Surgery, Centre Hospitalier de l'Université de Montréal, 1560 rue Sherbrooke Est, 8e CD - Pavillon Lachapelle, bureau D-8051, Montréal, Québec, Canada H2L 4M1 (E-mail: moishe.liberman@umontreal.ca).

0022-5223/\$36.00

Copyright (c) 2017 by The American Association for Thoracic Surgery

http://dx.doi.org/10.1016/j.jtcvs.2016.12.049
Pulmonary lobectomy is the primary treatment strategy for stage I and II non-small cell lung cancer. ${ }^{1}$ Video-assisted thoracoscopic surgery (VATS) is a minimally invasive approach for anatomic lung resection; however, it has not gained widespread clinical application. ${ }^{2}$ Pulmonary artery (PA) manipulation, dissection, and division represent a

Scanning this QR code will take you to a supplemental video. To view the AATS 2016 Webcast, see the URL next to the video thumbnail.

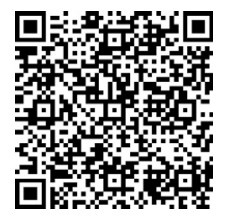




\section{Abbreviations and Acronyms \\ $\mathrm{ACE}=$ Harmonic Ace +7 Shears with Advanced Hemostasis \\ PA = pulmonary artery \\ VATS $=$ video-assisted thoracoscopic surgery}

stressful part of the operation due to the fragility of these vessels. Iatrogenic injury to a PA branch may cause dangerous intraoperative hemorrhage. Vascular endostaplers are typically used for PA division in VATS lobectomy. However, they require wide vessel dissection for application and are not user friendly in tight spaces around the pulmonary vasculature, especially when these branches are short and thin. Ultrasonic energy vessel-sealing devices have the potential to make PA branch sealing safer, especially for small and short vessels. They have a smaller footprint and require less vessel dissection compared with vascular endostaplers. This technique for PA branch sealing may make VATS lobectomy more appealing to thoracic surgeons.

The primary objective in this phase I clinical trial was to determine immediate and delayed seal failure of PA branch sealing and division with an ultrasonic energy vesselsealing device in open lobectomy.

\section{METHODS}

This study consists of a phase I clinical trial evaluating the safety of energy sealing lobar PA branches for lobectomy in humans with the Harmonic Ace +7 Shears with Advanced Hemostasis (ACE) (Ethicon, Cincinnati, Ohio) (Clinicaltrials.gov identifier: NCT02456311). All patients planned to undergo a lobectomy by thoracotomy at the Centre Hospitalier de l'Université de Montréal-Hôpital Notre-Dame, Montréal, Canada, were approached in an attempt to enroll them into this study. This study was approved by the Institutional Review Board at the Centre de Recherche du Centre Hospitalier de l'Université de Montréal, Québec, Canada. Written informed consent was obtained from each participant.

At the Centre Hospitalier de l'Université de Montréal, lobectomies are either performed by VATS, robotics, or by thoracotomy. This decision is based on surgeon preference, tumor size, tumor localization, and patient characteristics. Only patients planned for a lobectomy by thoracotomy were approached for enrollment into the trial.

We aimed to seal a minimum of a single PA branch with the ACE in 10 patients (Figure 1). The primary outcome was immediate and delayed seal failure of the PA branch stumps sealed and divided with the ACE. Immediate seal failure was defined as immediate and/or intraoperative bleeding from an ACE-sealed PA stump. Delayed seal failure was defined as a patient requiring reoperation in which bleeding was identified from a PA stump sealed with the ultrasonic vessel-sealing device. The secondary outcomes were 30- and 90-day morbidity and mortality, postoperative complications, and need for reoperation.

Because the current trial was a phase I study, the sample size was calculated to assess initial safety with the device in sealing PA branches in open lobectomy. A sample size of 10 patients was considered sufficient. The ultimate goal was to assess the device in VATS lobectomy. A larger sample size will be used in the next safety study evaluating VATS lobectomy.

The inclusion criterion was all patients planned to undergo a lobectomy by thoracotomy at the Centre Hospitalier de l'Université de
Montréal by a Thoracic Surgery Service thoracic surgeon. The exclusion criteria were age younger than 18 years and inability to consent to the study. Preoperative or postoperative anticoagulants were not a contraindication to recruitment.

Consented patients underwent open lobectomy following the standard operative steps the surgeon usually follows, except for sealing and dividing PA branches $\leq 7 \mathrm{~mm}$. Thoracotomy incision was performed in the location decided by the surgeon, according to anatomy and tumor location. Hilar dissection was performed in the usual fashion. It was permitted to use the energy device for hilar, fissure, and lymph node dissection. The lobar pulmonary vein(s) were divided with vascular staplers. The lobar PA branches were dissected and isolated using a vessel loop. The lobar PA branch diameter was then measured with a sterile ruler (Figure 2). If the diameter was $\leq 7 \mathrm{~mm}$, it was sealed and divided using the ACE (Figure 3, Video 1). PA branches with a diameter $\leq 5 \mathrm{~mm}$ were sealed using the Min button on the device (power setting 3). PA branches $>5 \mathrm{~mm}$ were sealed using the Advanced Hemostasis button on the device. All PA branches $>7 \mathrm{~mm}$ were divided in a standard fashion according to surgeon preference (eg, vascular stapler, clip, and suture). The lobar bronchus and the fissure were divided using mechanical staplers. When encountered, bronchial arteries were sealed with monopolar cautery or clips.

During all cases, a 4-0 Prolene suture (Ethicon) with SH (small half) needle was opened on the sterile field in case a vascular seal failure occurred.

All cases were recorded with a thoracoscopic $10 \mathrm{~mm}, 30^{\circ}$ camera at time of PA sealing with the ultrasonic vessel-sealing device.

Enrolled patients received standard postoperative care. Chest tube removal and discharge was decided on by the treating surgeon. Daily serum hemoglobin levels were routinely measured for the first 3 postoperative days.

Study outcome parameters were collected prospectively and included tumor size, intraoperative blood loss, procedure time, total number of PA vessels divided, postoperative complications, chest tube output, the need for reoperation, blood transfusions, hospital length of stay, and 30- and 90-day morbidity and mortality.

All patients were followed in the postoperative clinic by their treating surgeon.

\section{RESULTS}

Nineteen patients were approached over a 19-week period. One patient refused to participate, whereas 18 patients consented to participate in the study. Eight patients were not amenable to PA sealing with the ACE due to all PA branch diameters exceeding $7 \mathrm{~mm}(\mathrm{n}=2)$, lobectomy not performed because of intraoperative findings $(n=2)$, PA branch too close to tumor $(\mathrm{n}=1)$, or surgeon judging PA sealing with ultrasonic energy vessel-sealing device would be unsafe because of case complexity $(n=3)$. In these 3 cases, patients required pericardiectomy due to tumor invasion and it was decided intraoperatively to exclude these patients from the trial. In the 10 patients included in the study analysis, a total of 28 PA branches were divided, all sealing techniques included. Fourteen PA branches were sealed with the ACE. Fourteen other vessels were divided using another technique because of diameter exceeding $7 \mathrm{~mm}$. No vessel sealed with the ACE was reinforced with clips, sutures, glue, or any other technique.

Four men and 6 women were included in the study analysis. Mean patient age was 59 years (range, 38-72 years). 

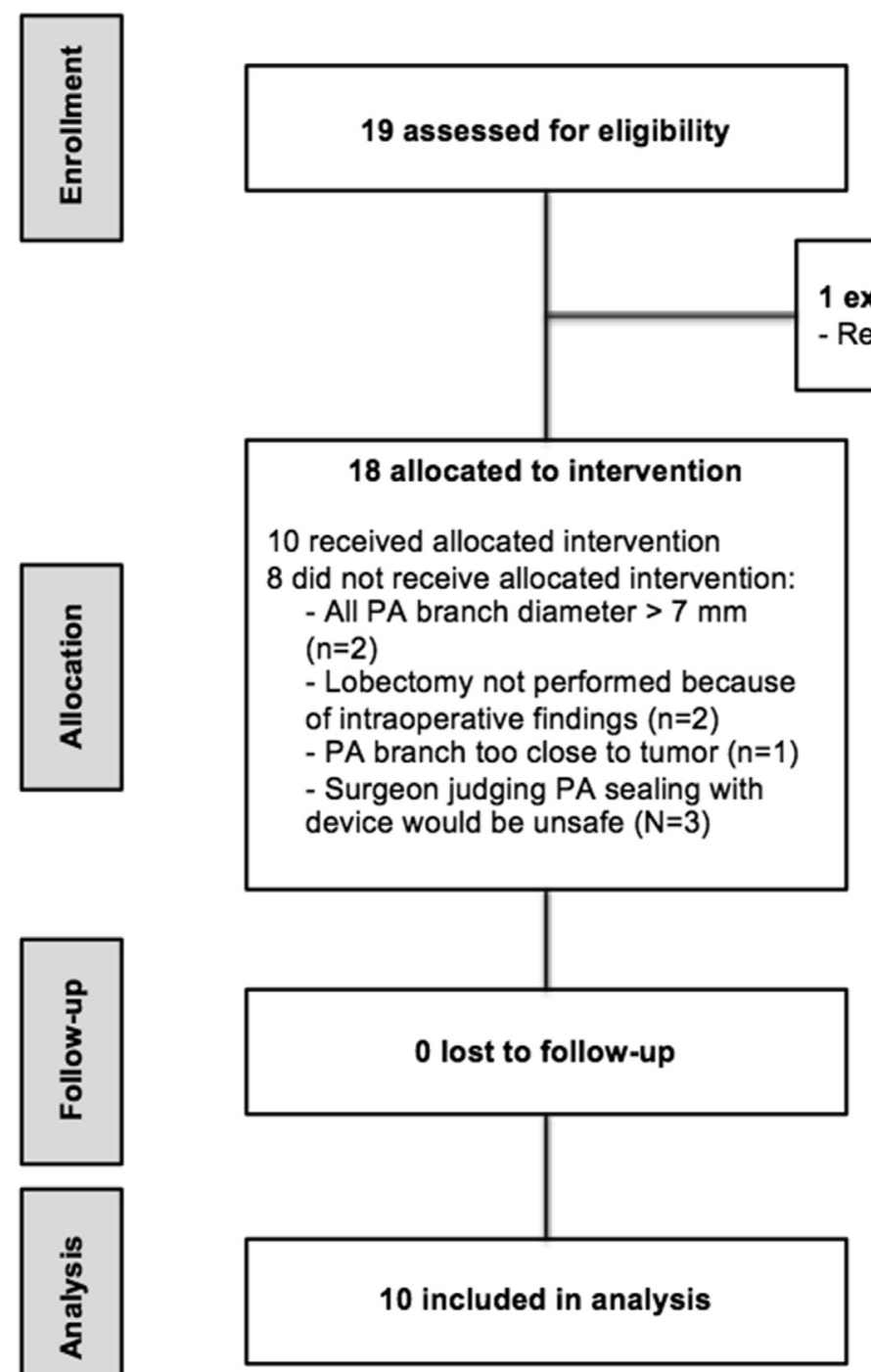

FIGURE 1. Flow diagram of the study. $P A$, Pulmonary artery.

Mean patient weight was $80 \pm 16 \mathrm{~kg}$ (range, $62-112 \mathrm{~kg}$ ). Tumor and vessel characteristics are detailed in Table 1 . Mean operative time was 108 minutes. Median length of stay was 7 days (range, 3-8 days).

Mean chest tube removal day was on postoperative day 4 (range, day 3-8). Mean chest tube output for the first 4 postoperative days was $400 \pm 207 \mathrm{~mL}, 287 \pm 180 \mathrm{~mL}$, $253 \pm 164 \mathrm{~mL}$, and $207 \pm 112 \mathrm{~mL}$, respectively. Mean intraoperative blood loss was $142 \mathrm{~mL}$ (range, $15-350 \mathrm{~mL}$ ). Mean hemoglobin level on postoperative day 1 was $115 \mathrm{~g} / \mathrm{L}$ (range, 92-135 g/L). Mean hemoglobin difference between preoperative value and postoperative day one was $16 \mathrm{~g} / \mathrm{L}$ (range, 5-26 g/L).

There were no immediate or delayed seal failures in any of the 14 PA branches sealed with the ultrasonic vessel-sealing device. The mean and median diameter of the ultrasonic sealed PA branches was $5 \mathrm{~mm}$ and $5 \mathrm{~mm}$, respectively (range, $2-7 \mathrm{~mm}$ ), and the median number of PA branches sealed with the device in each patient was 1 (range, 1-2). There was no 30- or 90-day mortality.

One patient who initially underwent a left upper lobe lobectomy with chest wall resection underwent reoperation on postoperative day 0 due to bronchial artery bleeding. The total blood loss was $4 \mathrm{~L}$. The patient received a total of 6 units of red blood cells and 4 units of fresh frozen plasma. The ACE sealed vessels were assessed and the seal was intact. There was an active bleed from a bronchial artery that was clipped and the bleeding stopped. Bronchial arteries had not initially been sealed with the ACE. This patient presented on postoperative day 9 with an empyema and underwent operation 1 week later for decortication 


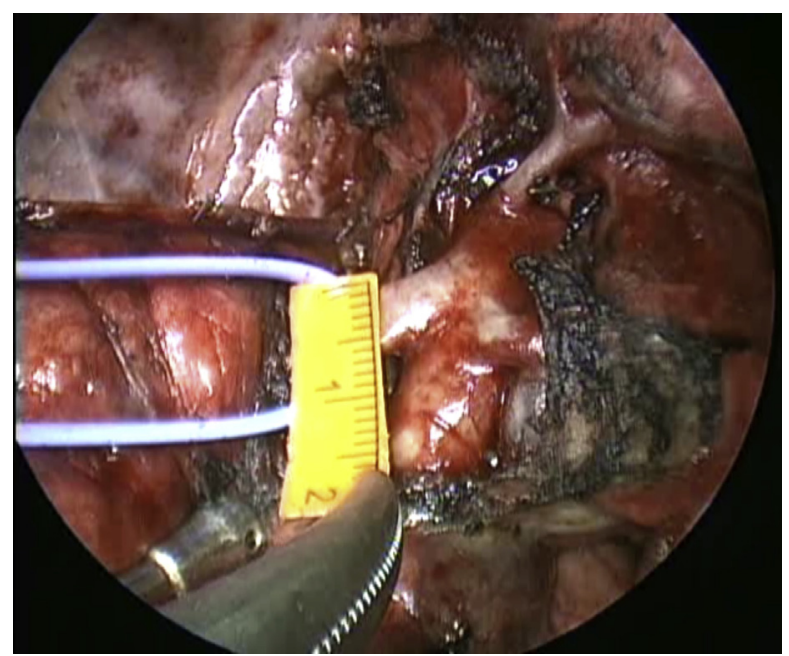

FIGURE 2. Pulmonary artery branch diameter measurement.

due to medical treatment failure. No other patients received blood transfusions.

One patient who underwent a right middle lobe lobectomy complicated with pneumonia and atrial fibrillation on postoperative day two. No other complication was observed.

\section{DISCUSSION}

This is the first prospective trial evaluating an ultrasonic energy vessel-sealing device without any reinforcement method for PA ligation for anatomic lung resection. The aim of this study was to determine the safety of the device in sealing and dividing PA vessels in open lobectomy. In this phase I clinical trial, we specifically selected patients who were scheduled to undergo lobectomy by thoracotomy for safety reasons. Because this was the first prospective human

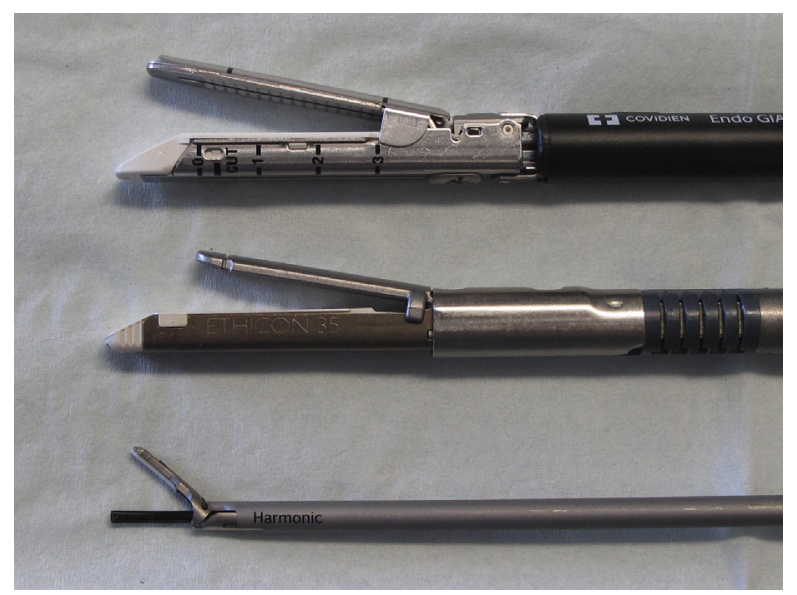

FIGURE 3. Comparison of instrument tip size. Top, Endo GIA $30 \mathrm{~mm}$ to $2.5 \mathrm{~mm}$ Stapler (Medtronic, Minneapoils, Minn). Middle, Endopath ETS $35 \mathrm{~mm}$ Stapler, (Ethicon, Cincinnati, Ohio). Bottom, Harmonic Ace +7 Shears with Advanced Hemostasis (Ethicon).

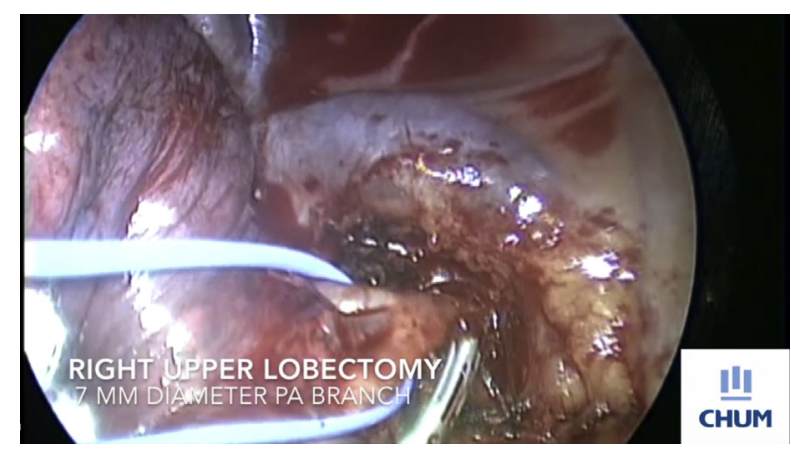

VIDEO 1. Pulmonary artery branch sealing with an ultrasonic energy vessel-sealing device in a right upper and a right middle lobectomy by thoracotomy. Video available at: http://www.jtcvsonline.org/article/S00225223(17)30177-0/addons.

trial using the ACE for PA sealing, an immediate seal failure would have been easier to control via thoracotomy compared with a VATS approach. However, the benefits of using ultrasonic energy vessel-sealing devices are potentially greatest when used during VATS lobectomy.

It is widely accepted that VATS lobectomy is associated with fewer postoperative complications, including atrial fibrillation, atelectasis, prolonged air leak, pneumonia, and renal failure compared with lobectomy by thoracotomy. VATS lobectomy is also associated with shorter chest tube duration and hospital length of stay. ${ }^{2-5}$ In an article published in 2013, ${ }^{2}$ according to the Nationwide Inpatient Sample database only $15 \%$ of anatomic lung resections in the United States were performed by VATS during 20072008. In Europe, the percentage of anatomic lung resections performed by VATS has been reported as similar. ${ }^{6,7}$ Since these numbers were published, the prevalence of VATS lobectomy has increased. However, this approach has still not been widely adopted by the thoracic surgeons community. ${ }^{8}$

A reason for the reluctance of some thoracic surgeons to adopt VATS lobectomy is related to PA manipulation, stapling, and division. Pulmonary vasculature ligation and division in VATS lobectomy is currently performed by most surgeons using vascular endostaplers. However, these devices are rigid, bulky, and are large instruments compared with some of the PA vessels that require division during pulmonary lobectomy. This can make the use of vascular endostaplers difficult and dangerous in certain situations, especially for small and short PA vessels. In a series published by Gazala and colleagues ${ }^{9}$ more than one-third of conversions from VATS to open lobectomy were secondary to PA injury. Conversion to thoracotomy can also occur to avoid complications when vessel stapling is judged unsafe by the surgeon. Other surgeons choose to perform open lobectomies to avoid finding themselves in such situations. Hence, we believe PA branch management in VATS lobectomy can be improved to make the procedure 
TABLE 1. Resected tumor and divided pulmonary arteries characteristics

\begin{tabular}{|c|c|c|c|c|c|c|c|}
\hline Patient & Lobe resected & Tumor histology & $\begin{array}{c}\text { Tumor } \\
\text { size }(\mathbf{m m}) *\end{array}$ & $\begin{array}{c}\text { PAs sealed } \\
\text { with ACE (n) }\end{array}$ & $\begin{array}{c}\text { Sealed PA } \\
\text { diameter }(\mathbf{m m})\end{array}$ & $\begin{array}{c}\text { PAs } \\
\text { stapled (n) } \\
\end{array}$ & $\begin{array}{c}\text { PAs } \\
\text { clipped (n) }\end{array}$ \\
\hline \multirow[t]{2}{*}{1} & RML/RLL & Squamous cell carcinoma (NSCLC) & 25 & 2 & 7 & 1 & 0 \\
\hline & & & & & 5 & & \\
\hline 2 & RUL & Adenocarcinoma (NSCLC) & 23 & 1 & 5 & 0 & 1 \\
\hline 3 & RUL & Granuloma & 27 & 1 & 5 & 1 & 0 \\
\hline \multirow[t]{2}{*}{4} & RML/RLL & Squamous cell carcinoma (NSCLC) & 100 & 2 & 6 & 2 & 0 \\
\hline & & & & & 3 & & \\
\hline 5 & RLL & Metastatic colorectal adenocarcinoma & 18 & 1 & 6 & 1 & 0 \\
\hline 6 & LUL & Myxoid sarcoma & 62 & 1 & 2 & 2 & 0 \\
\hline \multirow[t]{2}{*}{7} & RML & Adenocarcinoma (NSCLC) & 40 & 2 & 7 & 0 & 0 \\
\hline & & & & & 5 & & \\
\hline 8 & RUL & Squamous cell carcinoma (NSCLC) & 40 & 1 & 4 & 1 & 0 \\
\hline 9 & RLL & Adenocarcinoma (NSCLC) & 8 & 1 & 5 & 1 & 0 \\
\hline \multirow[t]{2}{*}{10} & LUL & Squamous cell carcinoma (NSCLC) & 65 & 2 & 3 & 4 & 0 \\
\hline & & & & & 6 & & \\
\hline
\end{tabular}

$P A$, Pulmonary artery; $A C E$, Harmonic Ace +7 Shears with Advanced Hemostasis (Ethicon, Cincinnati, Ohio); $R M L$, right middle lobe; $R L L$, right left lobe; $N S C L C$, non-small cell lung cancer; $R U L$, right upper lobe; $L U L$, left upper lobe. *Determined on preoperative chest computed tomography scan.

more user-friendly. A survey distributed among North American and European thoracic surgeons published in 2008 reported that the difficulty in the technique and the lack of evidence to establish safety of VATS lobectomy were among the most common causes explaining why this technique had not gained widespread popularity. ${ }^{10} \mathrm{~A}$ Japanese group ${ }^{11}$ evaluated intraoperative surgeon stress during VATS lobectomy in a randomized trial comparing 3 different vessel-sealing devices with proximal vessel clipping, which included the ACE, and standard vascular endostaplers. They found a significant surgeon stress reduction using a visual analog scale in the vessel sealing device group compared with the vascular endostapler group.

Despite the disadvantages of endostaplers, they are safe and effective instruments. Stapler-related complication rates are below $1 \% .{ }^{12-15}$ In a retrospective multicenter study, Yano and colleagues ${ }^{15}$ reported on 3393 endostapler applications on pulmonary vasculature. Eight adverse events occurred intraoperatively on pulmonary artery branches: oozing $(n=3)$, stapler failure $(n=2)$, compression causing peripheral vasculature laceration $(\mathrm{n}=2)$, and iatrogenic PA injury at insertion of the device $(n=1)$. There was 1 postoperative staple line rupture on a pulmonary vein stump. Another retrospective series reported a $0.27 \%$ endostapler-related complication rate based on 2548 endostapler applications on pulmonary vasculature in 713 patients. ${ }^{14}$ Reported complications included intimal fractures $(n=5)$, staple misfire $(n=1)$, and vessel avulsion $(\mathrm{n}=1)$. For energy sealing of PA vasculature to be considered as viable for lobectomy, low failure and complication rates will be necessary. Further data will need to be obtained to establish a similar safety profile as that established for endostaplers because the current study was a phase I study with a small sample size.
Other than endostaplers, endoclips can be used to achieve vascular sealing, especially on small vessels. They can be used in certain situation for PA sealing during lobectomy, but their use is limited in our opinion. Metal clips tend to slip and PA branches can be too short to apply 2 clips proximally. In situations where a clip would slip, the PA branch stump is often too short to easily control the bleeding. Hence, an ultrasonic energy vessel-sealing device is perhaps a better instrument to achieve permanent sealing of small PA branches.

The safety and effectiveness of ultrasonic energy vesselsealing devices for PA branch sealing has been reported in several ex vivo human lung specimen studies and animal studies. ${ }^{11,16-18}$ Burst pressure was measured on human PA stumps sealed with the ACE on lung specimens in a study published by our group. Ninety PA branches with a mean diameter of $5.2 \mathrm{~mm}$ (range, 1.7-11.4 mm) had a mean burst pressure of $333 \mathrm{~mm} \mathrm{Hg}$ (range, $84-1415 \mathrm{~mm} \mathrm{Hg}$ ) with no seal failure. ${ }^{17}$ Other studies with smaller sample size have shown similar results with bursting pressures far beyond physiological PA pressures. ${ }^{11,16}$

The ACE is approved for vessel sealing up to $7 \mathrm{~mm}$ diameter. A proper seal cannot be guaranteed for vessels larger than $7 \mathrm{~mm}$ due to the fitting of the vessel in the instrument jaws. In our protocol, we used the power setting 3 (Min button) for vessels up to $5 \mathrm{~mm}$ diameter. For vessels between 5 and $7 \mathrm{~mm}$ diameter, we used the Advanced Hemostasis function; Food and Drug Administration approval for the ACE to be used on these larger vessels is only with this function. An animal survival study published in 2007 showed the Harmonic ACE (Ethicon) (an earlier generation of the ACE used in our study) was safe to seal PA vessels up to $4 \mathrm{~mm}$ in diameter. ${ }^{18}$ In a total of 25 PA branches sealed, they had 6 seal failures. All of these failures occurred in vessels from 5 to $9 \mathrm{~mm}$ diameter. The authors suggest that these 
failures can be explained by the power setting used. Most failures were associated with a power setting at 2 , which causes a longer sealing time, but also causes more sticking to the instrument jaws. This sticking could have caused the failures. Since this study, the device has been improved and the jaws stick less to sealed tissue. Also, the Advanced Hemostasis mode was not available on their device. With this mode on the ACE, we can support safe sealing of PA vessels up to $7 \mathrm{~mm}$ diameter. ${ }^{19}$

The Advanced Hemostasis function has the advantage of being able to seal vessels up to $7 \mathrm{~mm}$ in diameter. However it has the disadvantage of having a longer sealing time and therefore a potential larger area of heat spread. Based on our experience, we find that there is more sticking when using this function compared with device power setting 3 . Therefore, we do not advocate the use of the Advanced Hemostasis function on all the vessels regardless of their diameter. We did not encounter a situation where the tip of the instrument was completely stuck to the wall of a sealed vessel. Letting the instrument cool down and gentle rotational movements always liberated the instrument tip from the sealed vessel.

A retrospective chart review reporting the experience of a single surgeon using an ultrasonic energy vessel-sealing device for pulmonary vessel ligation was recently published. ${ }^{20}$ Over a 6-year period, there were 97 PA vessels divided with the device and there was 1 seal failure. Diameter of divided vessels was not provided. Their criterion for safe application of the device was that the flattened vessel diameter had to be at least half the length of the instrument jaws. We agree that the vessel has to be properly flattened when the device is activated; however, the criterion that the vessel needs to be half the length of the instrument jaws seems conservative in our opinion. Vessels of 5 to $7 \mathrm{~mm}$ in diameter exceed this criterion and were included in our study. The ACE is designed to seal vessels up to $7 \mathrm{~mm}$ diameter and is approved by the Food and Drug Administration for systemic vessels up to and including $7 \mathrm{~mm}$.

Based on our experience in the animal lab, in ex vivo studies and in live humans with this ultrasonic energy vessel-sealing device, other technical details that we have developed include trying to apply the instrument to leave a long enough PA branch stump to be able to control a seal failure. Even when no seal failure occurs, surgeons are more comfortable having a stump to apply a clip if necessary. The PA branches being sealed with the device needs to be completely dissected circumferentially to limit the presence of surrounding tissue in the jaws of the device while activated. However, the dissection usually is less extensive than if an endostapler was used. Torque or tension must not be applied on the vessel while the device is activated to permit complete sealing. Keeping the device jaws closed and activated until the PA branch is completely divided also ensures complete sealing.
The ACE could potentially be useful for more than only PA branch sealing during lobectomy. In this trial, it was permitted to use the device for hilar and lymph node dissection, but not for bronchial artery sealing to avoid confounding in case of bleeding. It seems reasonable to also use it to seal bronchial arteries if judged appropriate by the surgeon. Just like for any surgical device, the surgeon must have the proper knowledge of the functioning and indications of the instrument and be aware of its limitations before using it.

Despite data from ex vivo studies, animal studies and human in vivo data supporting the safety of ACE in PA branch sealing, the use of the ACE or any other energy vesselsealing device for this indication should not be performed outside of a clinical trial. Additional in vivo data need to be collected before establishing a valid failure rate.

None of the complications in the present study that occurred in two patients were related to the use of the energy device. The patient population in this study selected for more complex cases given that all thoracic surgeons who participated in this trial also perform VATS lobectomy for the majority of their pulmonary lobectomies. Each recruited patient was planned for an open approach for a specific anatomic reason, which precluded VATS lobectomy. However, we do not believe this has an influence on our results for evaluating PA sealing and division with the ultrasonic energy device.

The active blade of the instrument becomes hot when activated on tissue. It can generate temperatures above $200^{\circ} \mathrm{C}$ and the blade remains hot a few seconds after activation. ${ }^{21}$ It is important not to put the active blade in contact with tissue that can potentially be harmed by heat during and after activation. This includes the airway, blood vessels, and nerves. Animal studies suggest a 3-mm safety margin around the tip of the instrument to avoid heat damage. ${ }^{21,22}$

All pulmonary veins were divided with vascular staplers. We believe there would be no major technical advantage to using the ultrasonic vessel-sealing device on pulmonary veins in VATS lobectomy. In our opinion, vascular endostaplers applied on these vessels do not carry the same complication risk as when applied to PA vessels.

\section{CONCLUSIONS}

In this trial, PA branch sealing for vessels with diameter of $7 \mathrm{~mm}$ or less was safely achieved with an ultrasonic energy vessel-sealing device in open lobectomy. This phase I safety trial was positive; no sealing failures in any PA branch sealed. The use of ultrasonic energy vessel-sealing devices in VATS lobectomy might have the advantage of making small, short, PA branch sealing safer than with vascular endostaplers. Further studies are necessary before widespread application in lobectomy, including VATS lobectomy. 


\section{Webcast}

You can watch a Webcast of this AATS meeting presentation by going to: http://webcast.aats.org/2016/Video/ Tuesday/05-17-16_Room_337_0830_Liberman-800.mp4.

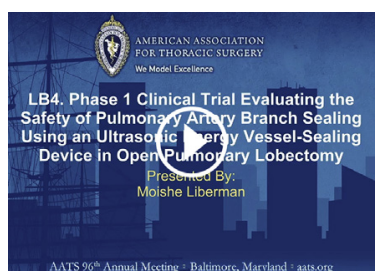

\section{Conflict of Interest Statement}

M.L. receives research and educational grants from Ethicon Endosurgery. All other authors have nothing to disclose with regard to commercial support.

\section{References}

1. Scott WJ, Howington J, Feigenberg S, Movsas B, Pisters K. Treatment of non-small cell lung cancer stage I and stage II: ACCP evidence-based clinical practice guidelines (2nd edition). Chest. 2007;132(3 Suppl): 234S-42S.

2. Paul S, Sedrakyan A, Chiu YL, Nasar A, Port JL, Lee PC, et al. Outcomes after lobectomy using thoracoscopy vs thoracotomy: a comparative effectiveness analysis utilizing the Nationwide Inpatient Sample database. Eur J Cardiothorac Surg. 2013;43:813-7.

3. Park BJ. Is surgical morbidity decreased with minimally invasive lobectomy? Cancer J. 2011;17:18-22.

4. Villamizar NR, Darrabie MD, Burfeind WR, Petersen RP, Onaitis MW, Toloza E, et al. Thoracoscopic lobectomy is associated with lower morbidity compared with thoracotomy. J Thorac Cardiovasc Surg. 2009;138:419-25.

5. Boffa DJ, Dhamija A, Kosinski AS, Kim AW, Detterbeck FC, Mitchell JD, et al. Fewer complications result from a video-assisted approach to anatomic resection of clinical stage I lung cancer. J Thorac Cardiovasc Surg. 2014; 148:637-43.

6. Gonzalez D, de la Torre M, Paradela M, Fernandez R, Delgado M, Garcia J, et al. Video-assisted thoracic surgery lobectomy: 3-year initial experience with 200 cases. Eur J Cardiothorac Surg. 2011;40:e21-8.

7. Page RD, McShane J, Kinsman R. Second national thoracic surgery activity \& outcomes report 2011. Society for Cardiothoracic Surgery in Great Britain \& Ireland. Henley-on-Thames: Dendrite Clinical Systems Ltd.

8. Ceppa DP, Kosinski AS, Berry MF, Tong BC, Harpole DH, Mitchell JD, et al. Thoracoscopic lobectomy has increasing benefit in patients with poor pulmonary function: a Society of Thoracic Surgeons Database analysis. Ann Surg. 2012;256: 487-93.

9. Gazala S, Hunt I, Valji A, Stewart K, Bedard ER. A method of assessing reasons for conversion during video-assisted thoracoscopic lobectomy. Interact Cardiovasc Thorac Surg. 2011;12:962-4.

10. Rocco G, Internullo E, Cassivi SD, Van Raemdonck D, Ferguson MK. The variability of practice in minimally invasive thoracic surgery for pulmonary resections. Thorac Surg Clin. 2008;18:235-47.

11. Toishi M, Yoshida K, Agatsuma H, Sakaizawa T, Eguchi T, Saito G, et al. Usefulness of vessel-sealing devices for $\leq 7 \mathrm{~mm}$ diameter vessels: a randomized controlled trial for human thoracoscopic lobectomy in primary lung cancer. Interact Cardiovasc Thorac Surg. 2014;19:448-55.

12. Asamura H, Suzuki K, Kondo H, Tsuchiya R. Mechanical vascular division in lung resection. Eur J Cardiothorac Surg. 2002;21:879-82.

13. Craig SR, Walker WS. Potential complications of vascular stapling in thoracoscopic pulmonary resection. Ann Thorac Surg. 1995;59:736-7; discussion 737-8.

14. Szwerc MF, Landreneau RJ, Santos RS, Keenan RJ, Murray GF. Minithoracotomy combined with mechanically stapled bronchial and vascular ligation for anatomical lung resection. Ann Thorac Surg. 2004;77:1904-9; discussion 1909-10.
15. Yano M, Takao M, Fujinaga T, Arimura T, Fukai I, Ota S, et al. Adverse events of pulmonary vascular stapling in thoracic surgery. Interact Cardiovasc Thorac Surg. 2013;17:280-4.

16. Liberman M, Khereba M, Goudie E, Kazakov J, Thiffault V, Lafontaine E, et al. Pilot study of pulmonary arterial branch sealing using energy devices in an ex vivo model. J Thorac Cardiovasc Surg. 2014;148:3219-23.

17. Liberman M, Khereba M, Nasir B, Goudie E, Danino A, Giot JP, et al. Pulmonary artery sealing using the HARMONIC ACE + shears for videoassisted thoracoscopic surgery lobectomy. Ann Thorac Surg. 2015;100: 898-903; discussion 904.

18. Nicastri DG, Wu M, Yun J, Swanson SJ. Evaluation of efficacy of an ultrasonic scalpel for pulmonary vascular ligation in an animal model. J Thorac Cardiovasc Surg. 2007;134:160-4.

19. Ethicon. HARMONIC ACE +7 Shears with Advanced Hemostasis. https:// www.ethicon.com/sites/default/files/managed-documents/010305-140214harmonic-ace-plus-7-detail-brochure.pdf. Accessed February 13, 2017.

20. White A, Kucukak S, Lee DN, Swanson SJ. Energy-based ligation of pulmonary vessels: a six-year experience with ultrasonic shears in videoassisted thoracoscopic lobectomy and segmentectomy. Ann Thorac Surg. 2016; 101:1334-7.

21. Kim FJ, Chammas MF Jr, Gewehr E, Morihisa M, Caldas F, Hayacibara E, et al. Temperature safety profile of laparoscopic devices: Harmonic ACE (ACE), Ligasure V (LV), and plasma trisector (PT). Surg Endosc. 2008;22: 1464-9.

22. Koch C, Friedrich T, Metternich F, Tannapfel A, Reimann HP, Eichfeld U. Determination of temperature elevation in tissue during the application of the harmonic scalpel. Ultrasound Med Biol. 2003;29:301-9.

Key Words: pulmonary artery sealing, energy, VATS lobectomy, ultrasonic energy

\section{Discussion}

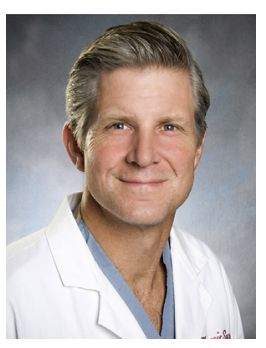

Dr Scott J. Swanson (Boston, Mass). Excellent protocol. Was that 1 center?

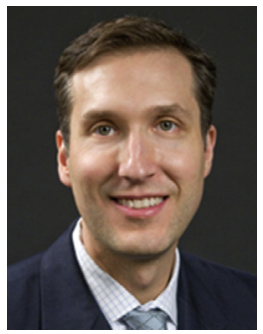

Dr Liberman. Single center. There are 5 surgeons involved.

Dr Swanson. I have 1 observation. We have been doing this for about 8 or 9 years and, similarly, have had no failures, all video-assisted thoracoscopic surgery. It seemed like you were using the slow mode, and we did find that there were some problems with that on occasion because it takes the time to do it, and the energy in the fast mode seems adequate, and what we found is that sometimes, in waiting for the slow mode to work, there is some movement. Now, it was perfect the way you guys were doing it, but sometimes we saw movement from the hilum and breathing or whatever, and that would tear and lead to injury. The fast mode in an animal model we published and then in our human series that we published last January has been really helpful. I do not know if you have any thoughts about that. 
Dr Liberman. In the past, using the slow mode, there were also issues with movement, but also with sticking, and with the newer devices, there is less sticking because the blades have been redesigned. As you get to 5, 6, and $7 \mathrm{~mm}$, there is no Food and Drug Administration approval, even for the slow mode, so we are using the Advanced Hemostasis mode at 5, 6, and $7 \mathrm{~mm}$. We have used the fast mode in the past and have found that we have had no problems using the slow mode, so $5 \mathrm{~mm}$ and under, we are on slow, and 5 to $7 \mathrm{~mm}$, we are using advanced.

Dr Kazuhiro Yasufuku (Toronto, Ontario, Canada). Thank you very much for the informative videos. I have been using a similar technique for some time, but I usually tie off the proximal end and just use the energy device for the distal end. I have not been brave like you.

You have lots of experience with those different kinds of energy devices. What is your experience with the other technology, for instance where ultrasound and bipolar energy is combined? Do you see any difference in your experience in patients?

Dr Liberman. Thanks a lot. Great question. We had published a comparative study looking at 4 different devices a few years back. We had a couple complete seal failures with some of the other devices. A complete seal failure is a devastating thing. That was obviously in an ex vivo situation, which nobody does, but obviously in this situation, we would be quite hesitant. With the advanced bipolar combined with ultrasound, we have had good results in an ex vivo, but we have not moved forward to the animal or the human live model. We have a study coming out, so I do not want to give all the data, but we find it very, very hot. When you are using the advanced bipolar with ultrasound, the heat and the lateral damage is much higher.

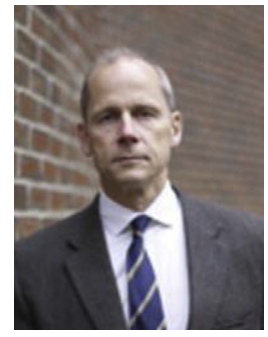

Dr Henning A. Gaissert (Boston, Mass). Do you use the tape just for demonstrating to us that it is $7 \mathrm{~mm}$ or do you use it also for yourself?

Dr Liberman. We do it for both. It is part of the study protocol, so we do measure the vessels. I think it is important, especially when you are reporting data, to know where those vessels are. We measure them all. I think it helps to show you what that vessel is, because on the screen it does not really portray the size. We measure all the vessels.

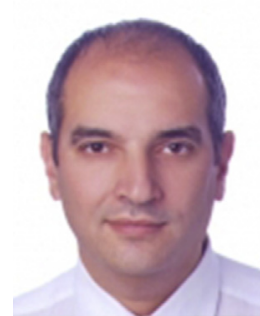

Dr Ehab Massad (Amman, Jordan). That was my question, about the measuring. I was in a meeting that included some general surgery and they could not agree on the measurement of the vessels. They were talking about the internal thoracic artery vessel and sealing the vessel and they could not agree on how wide that vessel was, and it is very difficult to gauge $7 \mathrm{~mm}$, especially on that magnification of the scope.

Dr Liberman. Thanks for the question. I appreciate it. There is definitely some or a lot of subjectivity in the measurement, even when we do it with a ruler, and I think that we appreciate that. Again, if it is $7.5 \mathrm{~mm}$, I do not think it makes any difference. I have sealed 13 -mm vessels in live animals without a problem. In the ex vivo and in animals, we usually use digital calipers, which are much more precise, but obviously in a sterile human setting, it is very difficult to use a digital caliper. We have looked at other devices and they were extremely complex and very annoying to sterilize, so we have gone to this disposable piece of paper ruler. Again, I do not think 7.5 or $8 \mathrm{~mm}$ makes a difference. We are just talking about Food and Drug Administration approval, but most of those approvals are not based on human studies anyway. 